\title{
Capacitor Placement and Sizing in Distorted Distribution Systems Using Simplified Direct Search Algorithm
}

\author{
Fitriana Suhartati, Dimas Fajar U. P., Ontoseno Penangsang, and Adi Soeprijanto
}

\begin{abstract}
In distribution systems, shunt capacitors are added in order to reduce the total active power loss and improve the power factor. However, the installation of shunt capacitors in distorted distribution systems will amplify the harmonics distortion level, if it is not placed in a proper location with harmonics consideration. Therefore, to take into account the presence of harmonic distortion, this paper proposes a simplified direct search algorithm to determine capacitors placement and sizing in distorted distribution systems. This algorithm is connected to harmonic power flow to search the proper location and size of shunt capacitors, which can decrease the total active power loss and increase the power factor, while the total harmonic distortion does not exceed the maximum allowable harmonic distortion level at each bus. To validate the method proposed, this algorithm is tested on 13-bus radial distribution system and 34-bus radial distribution system with harmonic current injection in order of 5, 7, 11, 13, and 17.
\end{abstract}

Index Terms - Shunt capacitors, active power loss, harmonic power flow, simplified direct search algorithm.

\section{INTRODUCTION}

In distribution systems, shunt capacitors are installed to compensate reactive power, reduce active power loss, adjust power factor, and improve voltage profile [1]. However, in radial distribution systems, the presence of harmonic distortion have to be considered for compensating reactive power by adding shunt capacitors. Because the installation of shunt capacitors in the distorted distribution systems can cause resonances, increase active power loss, extensive reactive power demand, and overvoltage, if determining the location and size of capacitors without considering the presence of harmonics in the systems [2].

Many research have taken into account the presence of harmonic current and voltage to optimize the placement and size of shunt capacitors using different methods, such as Genetic Algorithm(GA) [1], Genetic Algorithm with Fuzzy Logic (GA-FL) [2] and Fuzzy Set Theory (FST) [3] in a balanced three-phase systems. Moreover, in unbalanced three-phase system, Particle Swarm Optimization (PSO) [4] and Harmony Search Approach (HSA) [5] have been applied to find the optimal location and size of shunt capacitors in the distorted distribution systems.

Manuscript received August 20, 2013; revised December 16, 2013. This work was supported by Brawijaya University and Power Systems Simulation Laboratory, Department of Electrical Engineering, Sepuluh Nopember Institute of Technology (ITS).

Fitriana Suhartati is with Department of Electrical Engineering, Brawijaya University, Malang 65145 Indonesia (e-mail: fitrianas@ub.ac.id).

Dimas Fajar U. P., Ontoseno Penangsang, and Adi Soeprijanto are with the Power Systems Simulation Laboratory, Department of Electrical Engineering, Sepuluh Nopember Institute of Technology (ITS), Surabaya 60111 Indonesia. (e-mail: dimasfup@gmail.com).
This paper proposes a simplified direct search algorithm to determine the efficient location and size of capacitors [6] in distorted radial distribution systems, in order to minimize active power loss, improve power factor, and suppress the harmonic distortion level. The previous paper [6] applied a direct search algorithm for capacitive compensation in radial distribution systems, but the system does not contain any harmonics. In this paper, to consider harmonic distortion, a harmonic power flow algorithm based on backward-forward sweep technique [7] is implemented simultaneously with radial distribution power flow for the fundamental component [8].

\section{PROBLEM Formulation}

\section{A. Objective Function}

The objective function(1) is minimized to determine the efficient location and size of capacitors [9]:

$$
P_{l}=P_{l}^{(1)}+\sum_{h=h_{0}}^{h_{\max }} P_{l}^{(h)}
$$

where

$P_{l} \quad$ : total active power loss $(\mathrm{kW})$

$P_{l}^{(1)}$ : fundamental component of total active power loss $(\mathrm{kW})$;

$P_{l}^{(h)}$ : harmonic component of total active power loss $(\mathrm{kW})$;

$h \quad:$ the harmonic order;

$h_{0} \quad$ : the smallest harmonic order;

$h_{\max }$ : the highest harmonic order;

\section{B. Constraints}

In order to find the best location and size of shunt capacitors which not amplify the harmonic distortion, it is need to limit the power factor, The Total Harmonic Distortion (THD), and the number of compensators by the following constraints:

1) The power factor of each bus is not allowed less than 0.8 .

2) THD of each bus is kept less or equal to $5 \%$ as recommended by the IEEE standard 519-1992 [7].

The THD of the $i$ th bus is defined by [7]:

$$
\operatorname{THD}_{i}(\%)=\frac{\sqrt{\sum_{\substack{h_{\max } \\ h=h_{0}}}\left|V_{i}^{(h)}\right|^{2}}}{\left|V_{i}^{(1)}\right|^{2}}
$$

where $T H D_{i}$ : the total harmonic distortion of the $i$ th bus $(\%)$;

$\left|V_{i}^{(1)}\right|$ : the magnitude of bus voltage at the fundamental frequency;

$\left|V_{i}^{(h)}\right|$ : the magnitude of bus voltage at the harmonic

frequency;

$h_{0}, h_{\max }:$ the minimum and the maximum harmonic 
orders;

3) The reactive power injected by shunt capacitors should not exceed the total reactive power demand in the systems [4].

$$
\sum Q c<\sum Q
$$

where $\sum Q_{c}$ : total reactive power injection;

$\sum Q$ :total reactive power demand before injection;

The reactive power injection based on the standard capacitor sizes available in the literature (in $\mathrm{kVAr}$ ) are: 150 , $300,450,600,750,900$, etc [6].

\section{HARMONIC POWER FLOW}

Fig. 1 shows a single line diagram of a distorted $n$-bus radial distribution system.

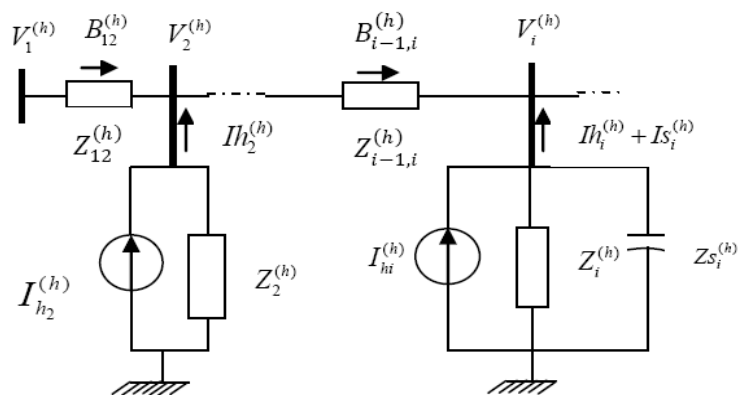

Fig. 1. A single line diagram of a distorted $n$-bus radial distribution system [7]

The harmonic current absorbed by the $i$ th bus shunt capacitor is expressed as [7]:

$$
\left[I s^{(h)}\right]=\left[I s_{i}^{(h)}\right]
$$

The $h^{\text {th }}$ harmonic current through the branches are given by:

$$
\left[I^{(h)}\right]=\left[\frac{I h^{(h)}}{I s^{(h)}}\right]
$$

The harmonic current through the branches is computed using the backward sweep approach expressed as follows (6):

$$
\left[\begin{array}{c}
B_{12}^{(h)} \\
\vdots \\
B_{i-2, i-1}^{(h)} \\
B_{i-1, i}^{(h)} \\
B_{i, i+1}^{(h)} \\
\vdots \\
B_{n-1, n}^{(h)}
\end{array}\right]=\left[\begin{array}{cccccccc}
1 & \ldots & 1 & 1 & 1 & \ldots & 1 & 1 \\
\vdots & \ldots & \ldots & \ldots & \ldots & \ldots & \ldots & \vdots \\
0 & \ldots & 1 & 1 & 1 & \ldots & 1 & 1 \\
0 & \ldots & 0 & 1 & 1 & \ldots & 1 & 1 \\
0 & \ldots & 0 & 0 & 1 & \ldots & 1 & 0 \\
\vdots & \ldots & \ldots & \ldots & \ldots & \ldots & \ldots & \vdots \\
0 & \ldots & 0 & 0 & 0 & \ldots & 1 & 0
\end{array}\right]\left[\begin{array}{c}
I h_{2}^{(h)} \\
\vdots \\
I h_{i-1}^{(h)} \\
I h_{i}^{(h)} \\
I h_{i+1}^{(h)} \\
\vdots \\
I h_{n}^{(h)} \\
I s_{i}^{(h)}
\end{array}\right]
$$

The $h^{\text {th }}$ harmonic branch current of any branch can be obtained by

$$
\left[B_{i j}^{(h)}\right]=\left[A_{i j}^{(h)}\right]^{T}\left[I^{(h)}\right]
$$

The coefficient vector of branch $i j$ is defined by:

$$
\left[A_{i j}^{(h)}\right]=\left[\frac{A h_{i j}^{(h)}}{A s_{i j}^{(h)}}\right]
$$

where $\left[A_{i j}^{(h)}\right]:$ the coefficient vector of branch $i j$;

$$
\left[A h_{i j}^{(h)}\right]: \text { the coefficient vector of branch } i j \text { due to the }
$$

harmonic current flows of the nonlinear and linear loads through branch $i j$;

$\left[A s_{i j}^{(h)}\right]:$ the coefficient vector of branch $i j$ due to the harmonic current absorbed by the shunt capacitors;

The coefficient vector consists of 0 and 1 only, for example if a bus harmonic current flows through the branch, then the corresponding position in the coefficient vector will be 1 .

The forward voltage sweep is utilized to obtain the harmonic bus voltage with respect to harmonic bus current injections as follows:

$$
\left[V^{(h)}\right]=\left[H A^{(h)}\right]\left[I^{(h)}\right]
$$

where $\left[V^{(h)}\right]$ : the harmonic bus voltages vector;

$\left[H A^{(h)}\right]$ : the relationship matrix between the harmonic bus voltages and system harmonic currents;

The harmonic bus voltages of the shunt capacitors are determined by:

$$
\left[V_{s}^{(h)}\right]=\left[H A_{s}^{(h)}\right]\left[\boldsymbol{I}^{(h)}\right]
$$

where

$\left[H A_{s}^{(h)}\right]$ : the row vectors of the matrix $\left[H A^{(h)}\right]$ associated with the buses at which shunt capacitors are installed, and the dimension is $1 x n$;

Therefore, $\left[H A_{s}^{(h)}\right]$ can be written as:

$$
\left[H A_{s}^{(h)}\right]=\left[H A_{s h}^{(h)} \vdots H A_{s s}^{(h)}\right]
$$

$\left[H A_{s h}^{(h)}\right]:$ the elements of $(n-1)$ columns in vector $\left[H A_{s}^{(h)}\right]$ are associated with the harmonic currents of the nonlinear and linear loads;

$\left[H A_{s S}^{(h)}\right]$ : the last element in $\left[H A_{s}^{(h)}\right]$ is related to the harmonic currents of the shunt capacitor at bus $i$;

The harmonic voltage on the $i$ th bus shunt capacitor is expressed in terms of the harmonic impedance of the shunt capacitor defined as:

$$
V s_{i}^{(h)}=-I s_{i}^{(h)} x Z s_{i}^{(h)}
$$

where

$I s_{i}^{(h)}$ : the harmonic current of the shunt capacitor on the $i$ th bus;

$Z s_{i}^{(h)}$ : the harmonic impedance of the shunt capacitor on the $i$ th bus;

The harmonic bus voltages are iteratively computed until a predefined threshold is reached.

$$
\left|V_{i}^{(h), k+1}-V_{i}^{(h), k}\right| \leq \varepsilon
$$

where

$V_{i}^{(h), k+1}:$ the harmonic voltage of the $i$ th bus at the $(k+1)$ th iteration;

$V_{i}^{(h), k}:$ the harmonic voltage of the $i$ th bus at the $k$ th iteration;

$$
k \quad: \text { the iteration; }
$$$$
\varepsilon \quad: \text { : the threshold; }
$$

The total active power loss for the $h^{\text {th }}$ harmonic order is:

$$
P_{l}^{(h)}=\left[R^{(h)}\right]^{T} \cdot \|\left.\left[A^{(h)}\right] \cdot\left[I^{(h)}\right]\right|^{2}
$$


where $\left[R^{(h)}\right]$ : the total branch resistance for the $h^{\text {th }}$ harmonic order.

\section{SimplifiEd DireCt SEARCH ALGORITHM}

According to the radial power flow analysis for the fundamental and harmonic components, the simplified direct search algorithm is implemented to find the efficient location and the size of the shunt capacitors. Based on the objective function(1), the algorithm can be described in these following steps:

1) The uncompensated loss in the system is considered maximum total active power loss.

2) Set the reactive power of all buses to zero or nearest zero by adding shunt capacitor (in $\mathrm{kVAr}$ ). This is considered as minimizing the total active power loss.

3) Try to find the location and size of capacitors in such away the total active power loss is measured and its value is between the maximum and minimum, however only the compensation which satisfy the constraints are listed.

4) The size of capacitors in the bus with the highest loss reduction will be reduced by multiple of the smallest capacitor size available.

5) Then, find the minimum total active power loss.

Fig. 2 below shows flowchart of the algorithm explained above.

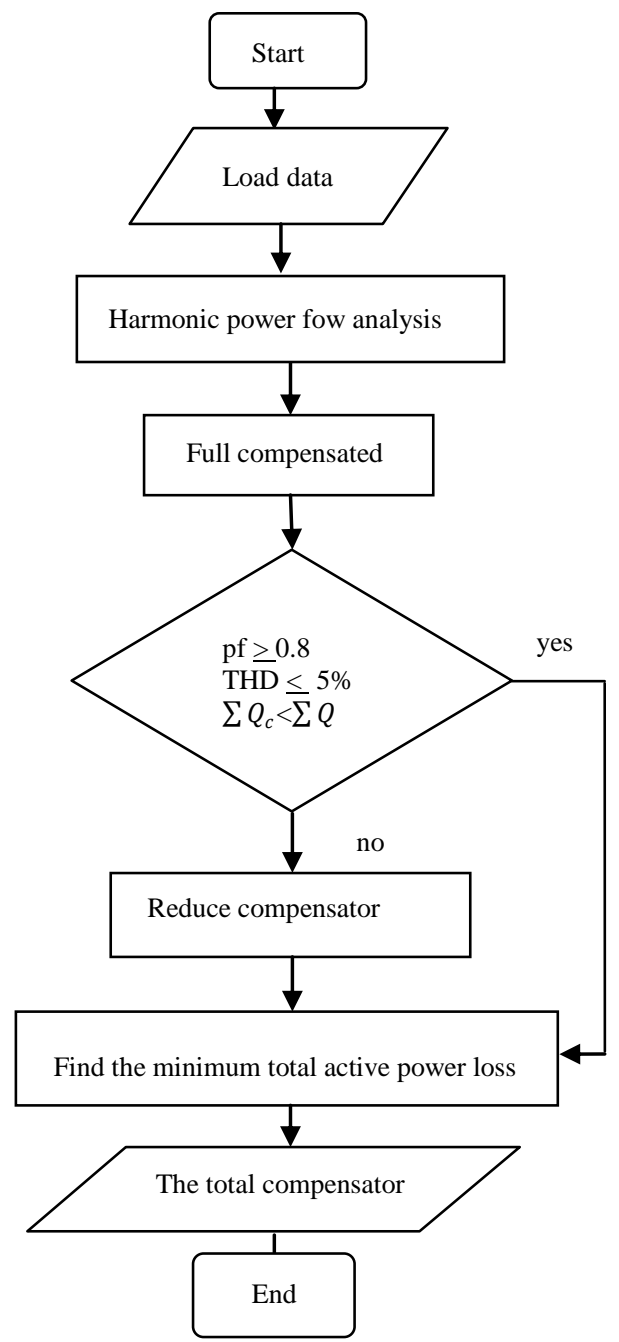

Fig. 2. Flowchart of simplified direct search algorithm.

\section{Simulation Results}

To validate the proposed method, the algorithm is applied to 13-bus test system and 34-bus test system as shown in Fig. 3 and Fig. 4 below.

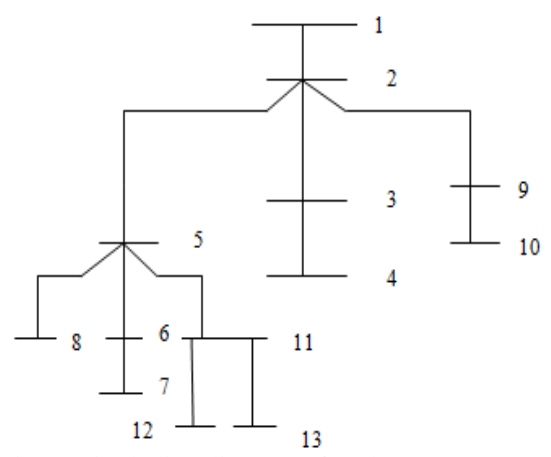

Fig. 3. Single line diagram of 13-bus test system.

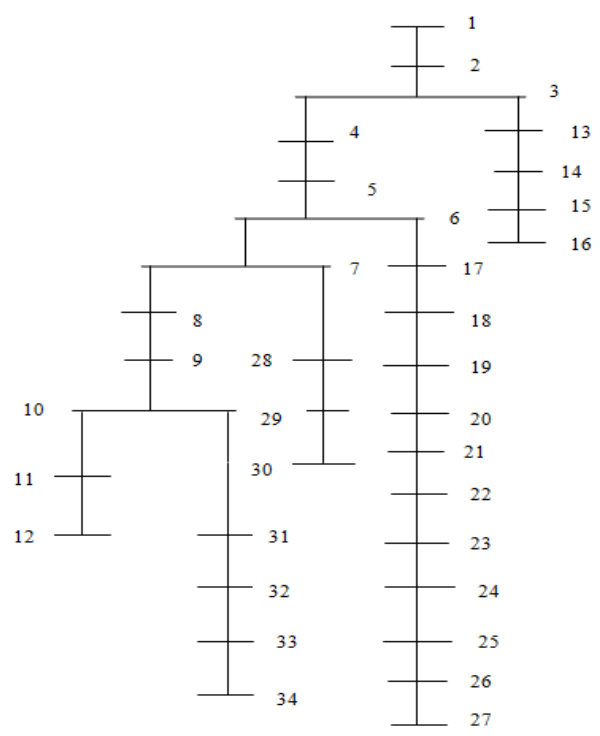

Fig. 4. Single line diagram of 34-bus test system.

\section{A. Test I: 13-Bus System}

In 13-bus test system, a harmonic current source was injected into bus 2 and 9. The harmonic injection current was in order of $5,7,11,13$, and 17. The load data of 13-bus system is listed in Table II (Appendix I).

In the uncompensated system, the measured total reactive power load in the 13-bus system was $4430 \mathrm{kVAr}$ and the total active power loss was $42.796 \mathrm{~kW}$. Using harmonic power flow analysis, the computed minimum $\cos \theta$ in the system was 0.15 and the maximum THD was $6.036 \%$.

Using the simplified direct search algorithm, the compensated system was constructed. The total reactive power injection in the system was $3750 \mathrm{kVAr}$ and the total active power loss reduced to $7.347 \mathrm{~kW}$. The minimum $\cos \theta$ in the system became 0.8 , whereas the maximum THD was $4.684 \%$, lower than uncompensated power loss.

\section{B. Test II: 34-Bus System}

Table III (Appendix I) shows the load data of 34-bus. In this bus test system, a harmonic current source was injected into bus 5, 11, 15, 25 and 33, with the harmonic injection current was in order of $5,7,11,13$, and 17.

In the uncompensated system, the measured total reactive power load in the 34-bus system was $4636.5 \mathrm{kVAr}$ and the total active power loss was $323.24 \mathrm{~kW}$. Using harmonic 
power flow analysis, the computed minimum $\cos \theta$ in the system was 0.771 and the maximum THD was $6.317 \%$.

After compensators were added into the system, the measured total reactive power injection in the system was $3150 \mathrm{kVAr}$, while the total active power loss became 205.9 $\mathrm{kW}$. The minimum $\cos \theta$ in the system was increased to 0.842 , whereas the maximum THD was reduced to $4.8 \%$.

\section{Comparison with Particle Swarm Optimization (PSO) Method}

TABLE I: THE COMPARISON OF REACTIVE COMPENSATION

\begin{tabular}{|c|c|c|c|}
\hline \multicolumn{4}{|c|}{ 13-Bus Systems } \\
\hline & $\begin{array}{l}\text { without } \\
\text { compensation }\end{array}$ & $\begin{array}{l}\text { compensation } \\
\text { by simplified } \\
\text { direct search }\end{array}$ & $\begin{array}{l}\text { compensation } \\
\text { by PSO }\end{array}$ \\
\hline $\mathrm{Q}$ total (kVAR) & 4430 & 3750 & 3600 \\
\hline Ploss total $(\mathrm{kW})$ & 42.796 & 7.347 & 7.829 \\
\hline $\cos \theta$ average & 0.535 & 0.938 & 0.907 \\
\hline THD average $(\%)$ & 4.675 & 3.993 & 3.995 \\
\hline \multicolumn{4}{|c|}{ 34-Bus Systems } \\
\hline Q total (kVAR) & 3633.5 & 3150 & 2400 \\
\hline Ploss total (kW) & 323.24 & 205.9 & 209.004 \\
\hline $\cos \theta$ average. & 0.829 & 0.968 & 0.938 \\
\hline THD average $(\%)$ & 4.119 & 3.173 & 3.255 \\
\hline
\end{tabular}

Table I shows the comparison between simplified direct search algorithm and particle swarm optimization (PSO) method to determine the efficient placement and size of shunt capacitors.

Using the proposed algorithm, the total power loss can be reduced in average of $35.449 \mathrm{~kW}$ for 13-bus system and $117.34 \mathrm{~kW}$ for 34 -bus system. It also increased the average power factor up to 0.403 in 13-bus system and 0.139 in 34-bus system. The decreasing of THD average until $0.682 \%$ for 13 -bus system and $0.946 \%$ for 34 -bus system can also be achieved. While compensation method using PSO reduced the average of total power loss to $34.967 \mathrm{~kW}$ for 13-bus system and $114.236 \mathrm{~kW}$ for 34-bus system. Increased the average power factor up to 0.372 in 13-bus system and 0.109 in 34-bus system and also decreased the THD average until $0.680 \%$ for 13 -bus system and $0.864 \%$ for 34 -bus system. However the total reactive power injection by the proposed method in 13-bus system was $150 \mathrm{kVAr}$ (greater than PSO), and $750 \mathrm{kVAr}$ (greater than PSO) in 34-bus system.

\section{CONCLUSION}

A simplified direct search algorithm for designing compensation in distorted distribution systems resulted the total active power loss reduction, power factor correction, and decreasing of total harmonic distortion level. These results were obtained from simulation for 13-bus and 34-bus systems. The simulation results have verified that the reactive compensation by simplified direct search algorithm yield slightly more reduction on the total active power loss and the THD compared to PSO, however the total reactive compensation by the proposed method was greater than PSO. A challenging research of the application of the proposed approach for unbalanced radial distribution systems is considered for future work.

\section{APPENDIX I}

TABLE II: LOAD DATA OF 13-BUS SYSTEMS

\begin{tabular}{ccccccc}
\hline \hline $\begin{array}{c}\text { Line } \\
\text { no. }\end{array}$ & $\begin{array}{c}\text { From } \\
\text { bus }\end{array}$ & $\begin{array}{c}\text { To } \\
\text { bus }\end{array}$ & $\mathrm{R}(\boldsymbol{\Omega})$ & $\mathrm{X}(\boldsymbol{\Omega})$ & $\mathrm{P}(\mathrm{kW})$ & $\mathrm{Q}(\mathrm{kVAR})$ \\
\hline 1 & 1 & 2 & 0.117 & 0.048 & 100 & 30 \\
2 & 2 & 3 & 0.107 & 0.044 & 20 & 730 \\
3 & 3 & 4 & 0.165 & 0.046 & 150 & 225 \\
4 & 2 & 5 & 0.150 & 0.042 & 50 & 10 \\
5 & 5 & 6 & 0.150 & 0.042 & 120 & 540 \\
6 & 6 & 7 & 0.314 & 0.054 & 40 & 700 \\
7 & 5 & 8 & 0.210 & 0.036 & 75 & 90 \\
8 & 2 & 9 & 0.314 & 0.054 & 50 & 150 \\
9 & 9 & 10 & 0.210 & 0.036 & 125 & 825 \\
10 & 5 & 11 & 0.131 & 0.023 & 210 & 800 \\
11 & 11 & 12 & 0.105 & 0.018 & 80 & 300 \\
12 & 11 & 13 & 0.157 & 0.027 & 95 & 30 \\
\hline \hline
\end{tabular}

TABLE III: LOAD DATA OF 34-BUS SYSTEMS

\begin{tabular}{|c|c|c|c|c|c|c|}
\hline $\begin{array}{l}\text { Line } \\
\text { no. }\end{array}$ & $\begin{array}{l}\text { From } \\
\text { bus }\end{array}$ & $\begin{array}{l}\text { To } \\
\text { bus }\end{array}$ & $\overline{\mathrm{R}(\Omega)}$ & $\mathrm{X}(\Omega)$ & "P(kW) & Q Q(kVAR) \\
\hline 1 & 1 & 2 & 0.117 & 0.048 & 230 & 190 \\
\hline 2 & 2 & 3 & 0.107 & 0.044 & 0 & 0 \\
\hline 3 & 3 & 4 & 0.165 & 0.046 & 230 & 190 \\
\hline 4 & 3 & 13 & 0.157 & 0.270 & 72 & 45 \\
\hline 5 & 4 & 5 & 0.150 & 0.042 & 230 & 190 \\
\hline 6 & 5 & 6 & 0.150 & 0.042 & 0 & 0 \\
\hline 7 & 6 & 7 & 0.314 & 0.540 & 0 & 0 \\
\hline 8 & 6 & 17 & 0.179 & 0.050 & 230 & 190 \\
\hline 9 & 7 & 8 & 0.210 & 0.036 & 230 & 190 \\
\hline 10 & 7 & 28 & 0.105 & 0.018 & 75 & 48 \\
\hline 11 & 8 & 9 & 0.314 & 0.540 & 230 & 190 \\
\hline 12 & 9 & 10 & 0.210 & 0.036 & 0 & 0 \\
\hline 13 & 10 & 11 & 0.131 & 0.023 & 230 & 190 \\
\hline 14 & 10 & 31 & 0.157 & 0.027 & 57 & 34.5 \\
\hline 15 & 11 & 12 & 0.105 & 0.018 & 137 & 84 \\
\hline 16 & 13 & 14 & 0.210 & 0.036 & 72 & 45 \\
\hline 17 & 14 & 15 & 0.105 & 0.018 & 72 & 45 \\
\hline 18 & 15 & 16 & 0.052 & 0.009 & 13.5 & 7.5 \\
\hline 19 & 17 & 18 & 0.165 & 0.046 & 230 & 190 \\
\hline 20 & 18 & 19 & 0.208 & 0.047 & 230 & 190 \\
\hline 21 & 19 & 20 & 0.189 & 0.043 & 230 & 190 \\
\hline 22 & 20 & 21 & 0.189 & 0.043 & 230 & 190 \\
\hline 23 & 21 & 22 & 0.262 & 0.045 & 230 & 190 \\
\hline 24 & 22 & 23 & 0.262 & 0.045 & 230 & 190 \\
\hline 25 & 23 & 24 & 0.314 & 0.540 & 230 & 190 \\
\hline 26 & 24 & 25 & 0.210 & 0.036 & 230 & 190 \\
\hline 27 & 25 & 26 & 0.131 & 0.023 & 230 & 190 \\
\hline 28 & 26 & 27 & 0.105 & 0.018 & 137 & 85 \\
\hline 29 & 28 & 29 & 0.105 & 0.018 & 75 & 48 \\
\hline 30 & 29 & 30 & 0.157 & 0.027 & 75 & 48 \\
\hline 31 & 31 & 32 & 0.210 & 0.036 & 57 & 34.5 \\
\hline 33 & 32 & 33 & 0.157 & 0.027 & 57 & 34.5 \\
\hline 33 & 33 & 34 & 0.105 & 0.018 & 57 & 34.5 \\
\hline
\end{tabular}




\section{ACKNOWLEDGMENT}

The authors would like to extend a highly grateful to Brawijaya Universtity for the financial contribution and to the Power Systems Simulation Laboratory, Department of Electrical Engineering, Sepuluh Nopember Institute of Technology (ITS), Surabaya, Indonesia to all facilities provided during this research.

\section{REFERENCES}

[1] M. A. S. Masoum, M. Ladjevardi, A. Jafarian, and E. F. Fuchs, "Optimal placement, replacement and sizing of capacitor banks in distorted distribution networks by genetic algorithms," IEEE Trans. Power Delivery, vol. 19, no. 4, pp. 1794-1801, Oct. 2004.

[2] M. Ladjevardi and M. A. S. Masoum, “ Genetically optimized fuzzy placement and sizing of capacitor banks in distorted distribution networks," IEEE Trans. Power Delivery, vol. 23, no. 1, pp. 449-456, Jan. 2008.

[3] M. A. S. Masoum, A. Jafarian, M. Ladjevardi, E. F. Fuchs, and W. M. Grady, "Fuzzy approach for optimal placement and sizing of capacitor banks in the presence of harmonics," IEEE Trans. Power Delivery, vol. 19 , no. 2, pp. 822-829, Apr. 2004

[4] A. E. Eajal and M. E. El-Hawary, "Optimal capacitor placement and sizing in unbalanced distribution systems with harmonics consideration using particle swarm optimization," IEEE Trans. Power Delivery, vol. 25, no. 3, pp. 1734-1740, July 2010.

[5] K. Muthukumar and S. Jayalalitha, "Harmony search approach for optimal capacitor placement and sizing in unbalanced distribution systems with harmonics consideration," in Proc. IEEE International Conference on Advance in Engineering, Science and Management, 2012, pp. 393-398.

[6] M. R. Raju, K. V. S. R. Murthy and K. Ravindra, "Direct search algorithm for capacitive compensation in radial distribution systems, " Electrical Power and Energy Systems, vol. 42, pp. 24-30, 2012.

[7] A. E. Eajal and M. E. El-Hawary, "Optimal capacitor placement and sizing in distorted radial distribution systems Part I: systems modeling and harmonic power flow studies," IEEE Trans. Power Delivery, 2010.

[8] J. H. Teng, "A network-topology-based three-phase load flow for distribution systems," Natl. Sci. Counc. ROC (A), vol. 24, no. 4, pp. 259-264, 2000

[9] A. E. Eajal and M. E. El-Hawary, "Optimal capacitor placement and sizing in distorted radial distribution systems Part II: problem formulation and solution method," IEEE Trans. Power Delivery, 2010.

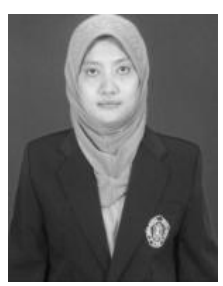

Fitriana Suhartati was born in Sidoarjo on $17^{\text {th }}$ October 1974. She has graduated from electrical engineering magister program at Sepuluh Nopember Institute of Technology, Surabaya, Indonesia, in 2003 Her major field of study is control systems.

Since 1998, she has teached in Electrical Engineering Department of Brawijaya University, Malang, Indonesia. She has many publications, and she had written a book with the title"Adaptive Control Systems" (TEUB, Malang, 2009). Her research interest is power quality in power distribution systems.

Suhartati becomes a member of Power Systems Simulation Laboratory, Department of Electrical Engineering, Sepuluh Nopember Institute of Technology (ITS), Surabaya, Indonesia, since 2012.

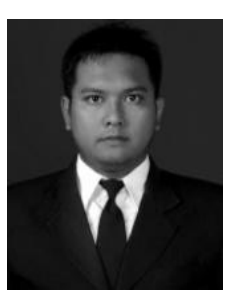

Dimas Fajar U. P. was born in Surabaya on $8^{\text {th }}$ November 1988. He has graduated from electrical engineering magister program at Sepuluh Nopember Institute of Technology, Surabaya, Indonesia, in 2012. His major field of study is power systems.

Since 2012, he has teached in Electrical Engineering Department of ITS, Surabaya, Indonesia. He has done many research and publications about power distribution systems. His research interest is about voltage stability index and load shedding in power distribution systems.

Fajar U. P. becomes a member of Power Systems Simulation Laboratory, Department of Electrical Engineering, Sepuluh Nopember Institute of Technology (ITS), Surabaya, Indonesia, since 2012.

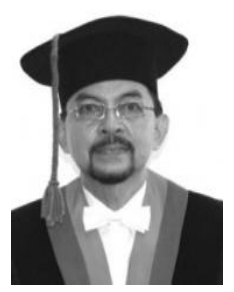

Ontoseno Penangsang was born in Madiun on $15^{\text {th }}$ July 1949. He had received his PhD of philosophy from University of Wisconsin, Madison, USA, in 1983. His major field of study is electrical power systems analysis.

Since 1974, he has teached in Electrical Engineering Department of ITS, Surabaya, Indonesia. He has done many research and publications about electrical power systems analysis. He had written a book with the title "Load Flow Analysis in Electrical Power Systems" (ITS press, Surabaya, 2013). His research interest is electrical power systems analysis and power quality.

Prof. Penangsang is the head of Power Systems Simulation Laboratory, Department of Electrical Engineering, Sepuluh Nopember Institute of Technology (ITS), Surabaya, Indonesia.

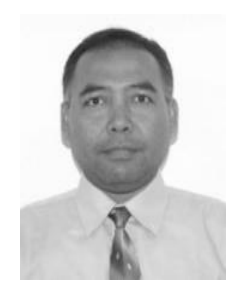

Adi Soeprijanto was born in Lumajang, on $5^{\text {th }}$ April 1964. He had received his $\mathrm{PhD}$ of Philosophy from Hiroshima University, Hiroshima, Japan, in 2001. His major field of study is electrical power systems controller.

Since 1990, he has teached in Electrical Engineering Department of ITS, Surabaya, Indonesia. He has done many research and publications about dynamic stability of electrical power systems. He had written a book with the title "Design Controller for Dynamic Stability of Electrica Power Systems" (ITS press, Surabaya, 2012). His research interest is dynamic stability of electrical power systems.

Prof. Soeprijanto is a director of post graduate program, Sepuluh Nopember Institute of Technology (ITS), Surabaya, Indonesia. He is also a member of Power Systems Simulation Laboratory, Department of Electrical Engineering, Sepuluh Nopember Institute of Technology (ITS). 